\title{
Expression of WW domain-containing oxidoreductase WOX1 in human nervous system tumors
}

\author{
Ming-Fu Chiang ${ }^{\mathrm{a}, \mathrm{c}}$, Shur-Tzu Chen ${ }^{\mathrm{d}}$, Chen-Peng Lo ${ }^{\mathrm{d}}$, Chun-I Sze ${ }^{\mathrm{e}}$, Nan-Shan Chang ${ }^{\mathrm{f}, \mathrm{g}, \mathrm{h}, *}$ \\ and Yu-Jen Chen ${ }^{\mathrm{b}, \mathrm{i}, *}$ \\ ${ }^{a}$ Department of Neurosurgery, Mackay Memorial Hospital, Taipei, Taiwan \\ ${ }^{\mathrm{b}}$ Department of Radiation Oncology, Mackay Memorial Hospital, Taipei, Taiwan \\ ${ }^{\mathrm{c}}$ Graduate Institute of Injury Prevention and Control, Taipei Medical University, Taipei, Taiwan \\ ${ }^{\mathrm{d}}$ Department of Cell Biology \& Anatomy, Nation Cheng Kung University, Tainan, Taiwan \\ ${ }^{\mathrm{e}}$ Department of Pathology, University of Colorado Health Sciences Center, Denver, CO, USA \\ ${ }_{\mathrm{f}}^{\mathrm{f}}$ Institute of Molecular Medicine, National Cheng Kung University College of Medicine, Tainan, Taiwan \\ ${ }^{\mathrm{g}}$ Guthrie Research Institute, Laboratory of Molecular Immunology, Sayre, PA, USA \\ ${ }^{\mathrm{h}}$ Department of Neuroscience and Physiology, SUNY Upstate Medical University, Syracuse, NY, USA \\ ${ }^{\mathrm{i}}$ Graduate Institute of Pharmacology, Taipei Medical University, Taipei, Taiwan
}

\begin{abstract}
.
BACKGROUND AND OBJECTIVES: We aimed to evaluate the expression levels of the tumor suppressor WOX1 in nervous system tumors and its co-expression with p53 and neurofibromatosis type 2/merlin (NF2) tumor suppressor gene products.

METHODS: Immunohistochemistry, western blotting and in situ hybridization were used for WOX1 protein and WWOX mRNA expression. Immunofluorescence and electron microscopical immunohistochemistry were performed for colocalization of gene products.

RESULTS: WOX1 expression is low in normal cortical neurons, mainly on the axon fibers, whereas there is moderate to high immunoreactivity in the cytosol and nuclei of certain tumor cells. In the microcystic (WHO grade I) and malignant (WHO grade III) meningiomas, WOX1 expression is intense, but various in transitional (WHO grade I) and atypical (WHO grade II) subtypes. WOX1 levels are moderate to high in the menigiotheliomatous area, but relatively low in the fibroblastic area. WOX1 and NF2/merlin, but not p53, colocalized in certain tumor cells, primarily at the borders of nuclei. Schwannoma and astrocytoma specimens stained moderately to strongly positive for the WOX1 protein. Interestingly, the expression of WOX1, NF2/merlin and mutant p53 is intense in high grade glioblastoma, but WOX1 expression is low in metastatic carcinoma or adenocarcinoma. CONCLUSIONS: The expression of WOX1 on different types of nervous system tumors, including primary and metastatic tumors, is differential.
\end{abstract}

Keywords: WOX1, NF2/merlin, tumor suppressor gene, meningioma, brain tumors

*Corresponding author: Yu-Jen Chen, M.D., Ph.D., Department of Radiation Oncology, Mackay Memorial Hospital. 92, Section 2, Chung-Shan North Road, Taipei 104, Taiwan. Tel.: +886 2 910699220; Fax: +886 2 28096180; E-mail: chenmdphd@ gmail.com; Nan-Shan Chang, Ph.D., Institute of Molecular Medicine, National Cheng Kung University College of Medicine, 1 University Road, Tainan 7010, Taiwan. Tel.: +886 6 2353535; Fax: +886 6 2751371; E-mail: changns@ mail.ncku.edu.tw. 


\section{Introduction}

The Human gene WWOX, located on a chromosomal fragile site (FRA16D), encodes a tumor suppressor WW domain-containing oxidoreductase WOX1, also known as WWOX or FOR [1-3]. Homozygous deletion of the human WWOX gene has been observed in several different cancers [1-7], indicating the chromosomal fragility of the WWOX gene plays an important role in tumorigenesis. The WWOX mRNA expression profile in epithelial ovarian cancer also supports the WWOX variant 1 as a tumor suppressor [8]. Alteration of the WOX1 gene product and its phosphorylation has been detected in various tumor tissues. For instance, during the progression of prostate and breast cancers from hyperplasia, cancerous to metastatic stages, WOX1 expression is upregulated [9]. In contrast, downregulation of the WOX1 protein and phosphorylation in squamous cell carcinoma has been observed [10]. However, it still remains unknown whether WOX1 gene products are present and function in nervous system tumors.

In vitro studies have shown that stress stimuli induce WOX1 phosphorylation followed by translocation to the mitochondria and nucleus [11]. Upregulated WOX1 interacts with tumor suppressor p53 and JNK1 in mediating apoptosis [12]. p73, the p53 homologue, was also found to physically interact with WOX1 via first WW domain and contributes to proapoptotic activity [5]. Recent studies further demonstrate that WOX1 binds and stabilizes p53 to regulate cell death with MDM2 involvement [13]. In the nervous system, WOX1 is highly expressed in developing CNS and PNS, but downregulated as adults, suggesting its role in neuronal development rather than apoptotic function [14]. We also detected that WOX1 is normally distributed in cortical fibers, striatal nerve bundles, corpus callosum and some projecting fibers in human and rodent brains, but low in astrocytes or other glia. Upregulation of WOX1 and its phosphorylation at Tyr33 was observed recently in light-induced retinal degeneration [15] and neurotoxin- and axotomy-induced neuronal injury (published data). In patients with AD, WOX1 expression was altered [16]. Demonstrated downregulation of WOX1 induced Tau phosphorylation and the formation of neurofibrillary tangles. These observations indicate that WOX1 plays multiple functions in modulating neuronal survival and death.

On the other hand, neurofibromatosis 2 (NF2) is an inherited disorder, caused by inactivating mutations of the NF2 gene, that predisposes the patient to the development of nervous system tumors such as meningioma and schwannoma [17]. Merlin, the $N F$ gene product, has been shown to interact with numerous proteins, involving a variety of cellular activities [18, 19]. For instance, NF2/merlin interacts with the actin cytoskeleton to modulate cell growth and motility. Besides, NF2/merlin efficiently inhibited Rac-induced colony formation and reduced JNK activity as well as Rac-induced AP-1 transcription [20]. These observations and an increase of Rac/JNK in schwannomas suggest that the regulation of NF2/merlin on Rac/JNK activation is important for schwannoma cell dedifferentiation [21]. Moreover, NF2/merlin increases p53 activity by inducing MDM2 degradation and could be a positive regulator of $\mathrm{p} 53$ [22]. As mentioned earlier, the activated p53 interacts with phosphorylated WOX1 and JNK1 to regulate apoptosis [12]. During stress response, the formation of a heterotrimeric complex p53/WOX1/JNK1 could be detected. More evidence indicates that WOX1 is involved in the regulation of p53 expression and its transcriptional target p21 [13]. It is intriguing to investigate whether tumor suppressor WOX1 interacts with mutant p53 in nervous system tumors. Meningiomas are common tumors on the coverings of the CNS. Several genes have been shown to carry mutations in meningiomas, with the NF2 gene being most frequently affected. In this study, the co-expression of WOX1, p53 and NF2/merlin status in meningiomas was also investigated. A positive correlation between the grades of tumor malignancy and the levels of WOX1 expression was detected, suggesting that WOX1 may play an important role in tumorigenesis.

\section{Materials and methods}

\subsection{Clinical cases}

Consecutive cases and samples of nervous system tumors were retrospectively retrieved from the tissue bank of the Department of Neurosurgery, Mackay Memorial Hospital, Taiwan. They were 15 meningiomas, 5 schwannomas, 10 astrocytomas/gliobalstomas/ependymomas, 2 melanomas, and 6 metastatic adenocarcinomas. All cases were independently reviewed by two of the pathologists. Meningiomas were classified according to WHO criteria as benign, atypical and malignant. This study has been approved by the institutional review board of Mackay Memorial Hospital, Taiwan. 


\subsection{Immunohistochemistry and western blottings}

Immunohistochemistry of brain tumor sections was performed as described [14, 15]. Briefly, deparaffined sections were incubated with aliquots of diluted antisera against an $N$-terminal region of WOX1 or a phospho-Tyr33 WOX1 peptide (p-WOX, 1/600 dilution) $[11,12]$. Both avidin-biotin peroxidase technique and glucouse-oxidase-nickel-diaminobenzidine (DAB) enhancement were used to detect antigenantibody complexes. Negative controls included: 1) staining the test tissues with non-immune serum, and 2) preadsorbing the antiserum with an immunizing, synthetic peptide $(20 \mathrm{nmol} / \mathrm{ml})$. Where indicated, serial sections were stained with antibodies against mutant p53 (Pab 240), NF2/merlin (C-18, Santa Cruz) and WOX1. Alterations of the expression of both proteins were examined under fluorescence microscopy.

For immunoblotting, brain tissues, from patients with nervous system tumors or normal controls, were extracted with a lysis buffer containing $5 \mathrm{mM}$ Tris ( $\mathrm{pH} 8.5), 2 \%$ SDS and $10 \%$ glycerol. Equal amounts of proteins from each sample were subjected to electrophoresis and transferred onto nitrocellulose membranes. The membranes were then incubated with aliquots of WOX1 or NF2/merlin antisera $(1: 2000$ dilution), followed by staining with horseradish peroxidase-conjugated goat anti-rabbit IgG. The reaction was visualized using an ECL detection kit (ECL, Amersham).

\subsection{Electron microscopical immunocytochemistry (Immuno-EM)}

For the EM study, the tumor tissue was fixed with a freshly prepared $1 \%$ solution of glutaraldehyde and $4 \%$ paraformaldehyde in $0.1 \mathrm{M}$ phosphate buffer, and subsequently fixed in $1 \%$ of osmium tetroxide, dehydrated in a graded series of ethanol and embedded in Quetol 812 according to a standard protocol $[14,15]$. Ultrathin sections (70-80 nm) were prepared with an ultramicrotome (Reichert-Jung, Austria) and labeled with WOX1 or NF2/merlin antibodies, followed by detecting with anti-goat $10 \mathrm{~nm}$ or anti-rabbit $20 \mathrm{~nm}$ protein A-gold probes (British Biocell International). The sections were stained with saturated aqueous uranyl acetate and lead citrate at room temperature. Specimens were then observed under a transmission electron microscopy (JEOL JEM-1200EX, Japan) at $100 \mathrm{kV}$.

\subsection{Generation of complementary RNA (cRNA) probes and in situ hybridization}

Total RNAs were isolated from 6 cases of meningiomas and 2 human cortical tissues by Trizol reagent (Invitrogen). Two $\mu \mathrm{g}$ of total RNA from the specimens were reverse-transcribed. Single-stranded, digoxigenin-labeled WOX1 cRNA probes were generated using a two-step PCR amplification and in vitro RNA transcription [10]. Briefly, amplification for 35 cycles under standard conditions was performed by the following primer pairs: WOX1 (sense) 5'-AAAACGACTATTGGGCGATG-3'; T7+ WOX1 (antisense) 5'-ACTCACTATAGGGAGAGTGT TGGAGGGACATTTGGA- $3^{\prime}$. The purified PCR product was further amplified using the above sense primer of WOX1 and another composite primer (universal $\mathrm{T} 7: 5^{\prime}$-TAAGCTTTAATACGACTCACTAT $\left.A G G G A G A-3^{\prime}\right)$ to extend and complete the full-length 23 -bp T7 promoter. One $\mu \mathrm{g}$ of secondary PCR products served as templates for RNA transcription using a DIG RNA Labeling Kit (Roche). A sense cRNA probe was made for negative controls. The generated antisense or sense cRNA was used for in situ hybridization and the signals were detected using an immunoassay kit (Roche). The extent of WWOX mRNA expression was analyzed as indicated above.

\section{Results}

\subsection{WOX1 expression and Tyr 33 phosphorylation in nervous system tumors}

Tumor characteristics of different tumors were determined by hematoxylin and eosin stains. Table 1 shows the diagnosis of meningiomas, schwannomas, astrocytomas and ependymomas. Here, we examined first the WOX1 expression in the brain tissues obtained from normal cortical regions and tumors. In general, the levels of WOX1 expression were low in neurons and glia. Moderate immunoreactivity was present on the nerve fibers, including the axons of cortical pyramidal cells, striatal nerve bundles, corpus callosum and some projecting fibers (Fig. 1a). The staining profile resembled that observed in the rodent nervous system. Upregulation of WOX1 and Tyr 33-phosphorylated WOX1 ( $p$-WOX) was observed in most of the collected nervous system tumors, including astrocytomas and meningiomas (Figs. 1-4). According to the WHO classification of meningioma, the fibroblastic, transitional 
Table 1

Clinical data of brain tumor patients

\begin{tabular}{|c|c|c|c|c|c|c|c|}
\hline No & Sex & Age & Diagnosis & WOX1/p-WOX & NF2 & $\mathrm{p} 53$ & $\mathrm{Bcl}-2$ \\
\hline 1 & $\mathrm{~F}$ & 74 & meningioma, fibroblastic type & + & \pm & \pm & - \\
\hline 2 & $\mathrm{~F}$ & 69 & meningioma, transitional type & ++ & \pm & + & - \\
\hline 3 & M & 14 & meningioma, transitional type & + & ++ & \pm & \pm \\
\hline 5 & $\mathrm{~F}$ & 61 & meningioma, transitional type & ++ & \pm & \pm & \pm \\
\hline 6 & $\mathrm{~F}$ & 55 & meningioma, transitional type & ++ & + & + & + \\
\hline 7 & $\mathrm{~F}$ & 76 & meningioma, transitional type & + & ++ & \pm & \pm \\
\hline 8 & $\mathrm{~F}$ & 48 & meningioma, transitional type & ++ & + & ND & ND \\
\hline 9 & $\mathrm{~F}$ & 45 & meningioma, transitional type & ++ & + & + & ND \\
\hline 10 & $\mathrm{~F}$ & 79 & meningioma, transitional type & ++ & ++ & + & \pm \\
\hline 11 & $\mathrm{~F}$ & 62 & meningioma, transitional type & ++ & \pm & ND & ND \\
\hline 4 & $\mathrm{~F}$ & 75 & meningioma, microcystic & +++ & ++ & +++ & +++ \\
\hline 12 & M & 82 & atypical meningioma & ++ & \pm & \pm & + \\
\hline 13 & $\mathrm{~F}$ & 38 & atypical meningiomas & ++ & \pm & \pm & + \\
\hline 14 & M & 50 & malignant meningiomas & +++ & ++ & +++ & +++ \\
\hline 15 & M & 13 & neurilemoma (schwannoma) & +++ & + & ND & \\
\hline 16 & $\mathrm{~F}$ & 70 & neurilemoma (schwannoma) & ++ & ++ & + & \\
\hline 17 & $\mathrm{~F}$ & 41 & neurilemoma (schwannoma) & ++ & \pm & + & \\
\hline 18 & $\mathrm{~F}$ & 65 & neurilemoma (schwannoma) & ++ & + & ++ & \\
\hline 19 & $\mathrm{~F}$ & 75 & neurilemoma (schwannoma) & ++ & + & + & \\
\hline 20 & $\mathrm{~F}$ & 75 & pituitary adenoma & + & ++ & + & \\
\hline 21 & M & 74 & pituitary adenoma & ++ & ++ & ++ & \\
\hline 22 & $\mathrm{~F}$ & 27 & astrocytoma, Grade & ++ & \pm & \pm & \\
\hline 23 & M & 54 & astrocytoma, Grade & ++ & \pm & \pm & \\
\hline 24 & M & 49 & astrocytoma, GradeII & +++ & \pm & + & \\
\hline 25 & M & 6 & anaplastic astrocytoma, Grade III & +++ & + & \pm & \\
\hline 26 & M & 38 & anaplastic astrocytoma, Grade III & +++ & + & +++ & \\
\hline 27 & $\mathrm{~F}$ & 90 & glioblastoma multiforme, Grade IV & ++ & +++ & + & \\
\hline 28 & M & 69 & glioblastoma multiforme, Grade IV & +++ & ++ & ++ & \\
\hline 29 & $\mathrm{~F}$ & 57 & ependymoma & ++ & + & +++ & \\
\hline 30 & $\mathrm{~F}$ & 26 & ependymoma & + & ++ & ++ & \\
\hline 31 & M & 25 & ependymoma & + & + & \pm & \\
\hline 32 & $\mathrm{~F}$ & 62 & malignant melanoma & ++ & ++ & \pm & \\
\hline 33 & $\mathrm{~F}$ & 43 & malignant melanoma & ++ & +++ & + & \\
\hline 34 & M & 49 & craniopharyngeoma, embryonal tumor & + & ND & ND & \\
\hline 35 & M & 11 & rhabdomyosarcoma, embryonal tumor & + & ND & + & \\
\hline 36 & $\mathrm{~F}$ & 51 & metartatic adenocarcinoma & ++ & & & \\
\hline 37 & M & 85 & metastatic adenocarcinoma & \pm & & & \\
\hline 38 & $\mathrm{~F}$ & 52 & metastatic renal cell carcinoma & ++ & & & \\
\hline 39 & M & 78 & metastatic carcinoma, poorly differentiated & + & \pm & \pm & \\
\hline 40 & M & 66 & metastatic adenocarcinoma & + & & & \\
\hline 41 & M & 6 & metastatic tumor & + & + & + & \\
\hline
\end{tabular}

By WHO classification of meningioma, the fibroblastic, transitional and microcystic are classified as Grade I. Atypical and malignant meningiomas are classified as Grade II and III, respectively.

and microcystic are classified as Grade I. Atypical and malignant meningiomas are classified as Grade II and III, respectively. High levels of WOX1 and p-WOX were detected in certain types, such as microcystic and malignant meningiomas. In the microcystic meningiomas, the paucicellular collagenous tissues with a sparse population of spindle cells were immunostained weakly. WOX1 immunoreactivity was mainly present in the cytosol of polygonal moderate to large cells with oval or round nuclei (Fig. 1b). WOX1 expression was also detected in the nuclei of some small cells (Fig. 1c). Perivascular hyalinization was negative for WOX1, but smooth muscles were immunoreactive in some large blood vessels (data not shown). In the malignant cases, many small whorls were scattered in the tumor. Differential WOX1 expression appeared in the meningothelial cells of lobules or clusters in various shapes or sizes (Fig. 1d, e). For instance, mod- 


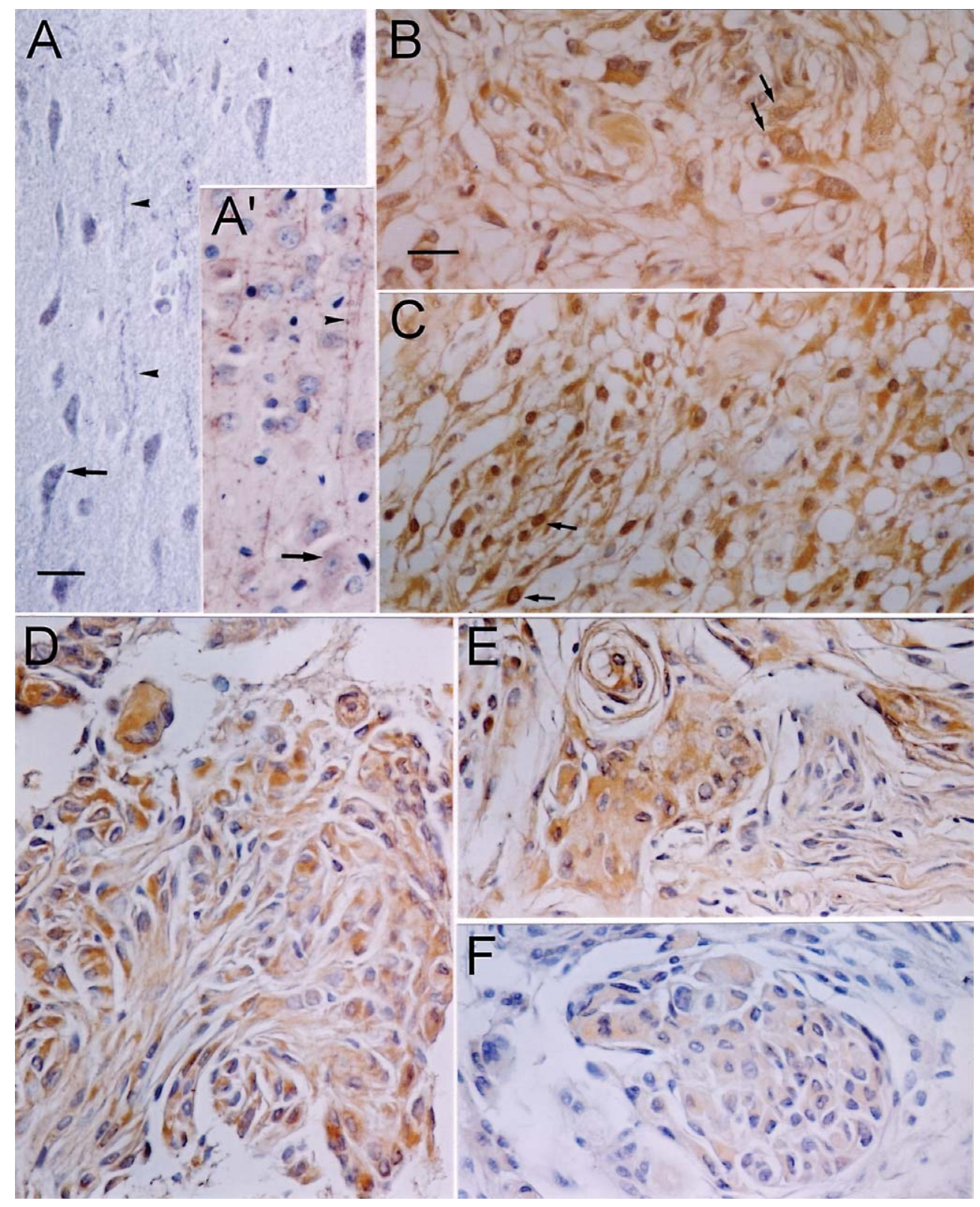

Fig. 1. WOX1 immunoreaction in normal control (a) and brain tumors (b-e). In normal human (a) and murine (a') brains, WOX1 was moderately present on the nerve fibers, such as the axons of pyramidal cells (arrowheads), whereas the staining intensity was low in cortical neurons (arrows). High levels of WOX1 were detected in microcystic (b, c) and malignant (d, e) meningiomas. In the microcystic meningiomas (b, c), WOX1 expression appeared in the cytosol of polygonal small to large cells with oval or round nuclei (arrows). Perivascular hyalinization was negative for WOX1, but endothelial cells and smooth muscles were immunoreactive in some large blood vessels (data not shown). In the malignant cases (d, e), many small whorls were scattered in the tumor. Moderate to high staining intensity was observed in the small whorls in storiform arrangement, whereas low levels of WOX1 appeared in the spindle cells with elongated nuclei around the outer portion. A similar pattern for $\mathrm{NF} 2 /$ merlin expression in the cluster of malignant meningiomas was also observed $(\mathrm{F})$. Bar $=50 \mu \mathrm{m}$.

erate to high staining intensity was observed in the small whorls with storiform arrangement, whereas low levels of WOX1 appeared in the spindle cells with elongated nuclei around the outer portion. Figure $1 \mathrm{~F}$ shows NF2/merlin expression in a cluster of malignant meningioma, resembling that of WOX1/p-WOX. 


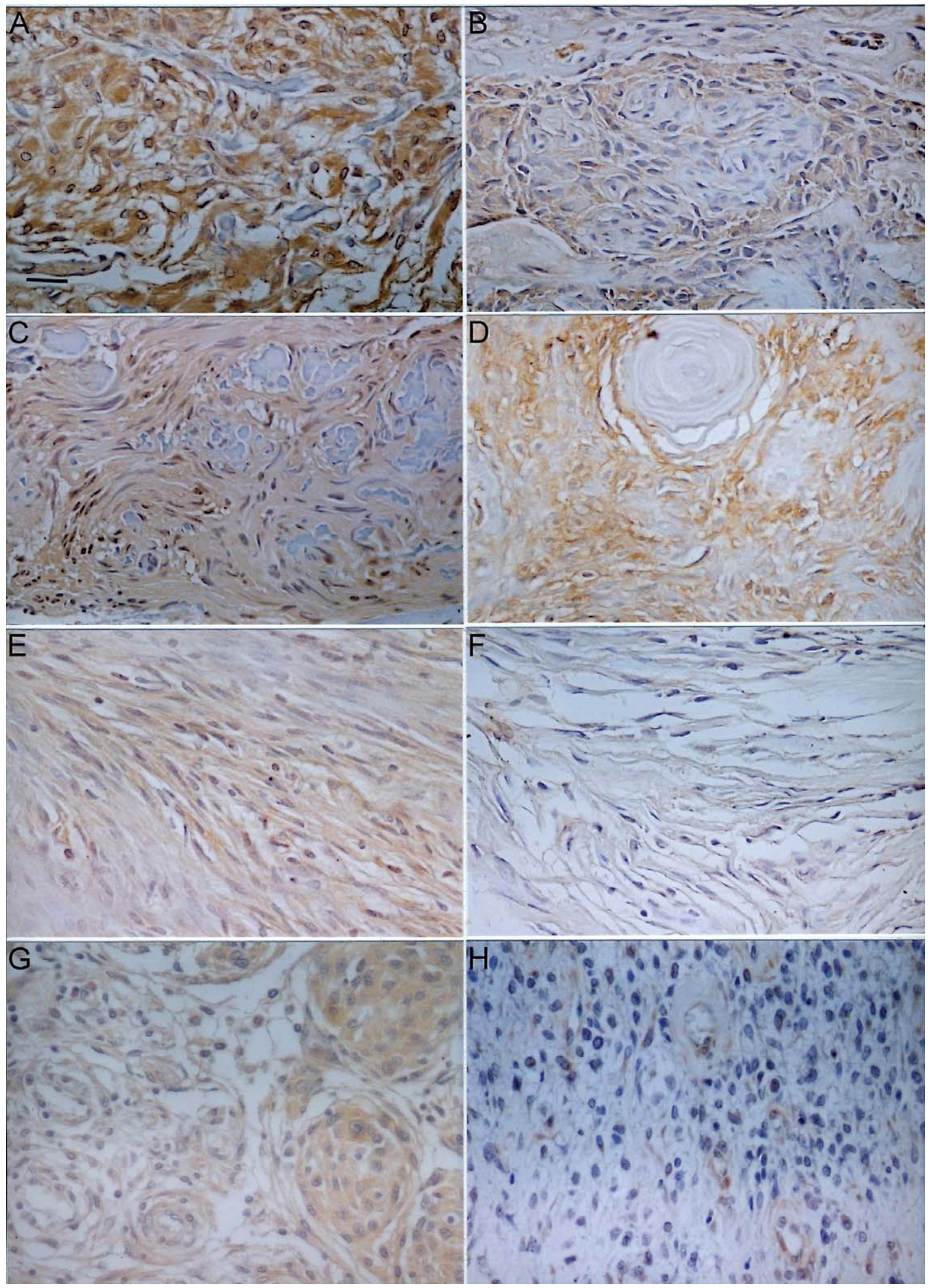




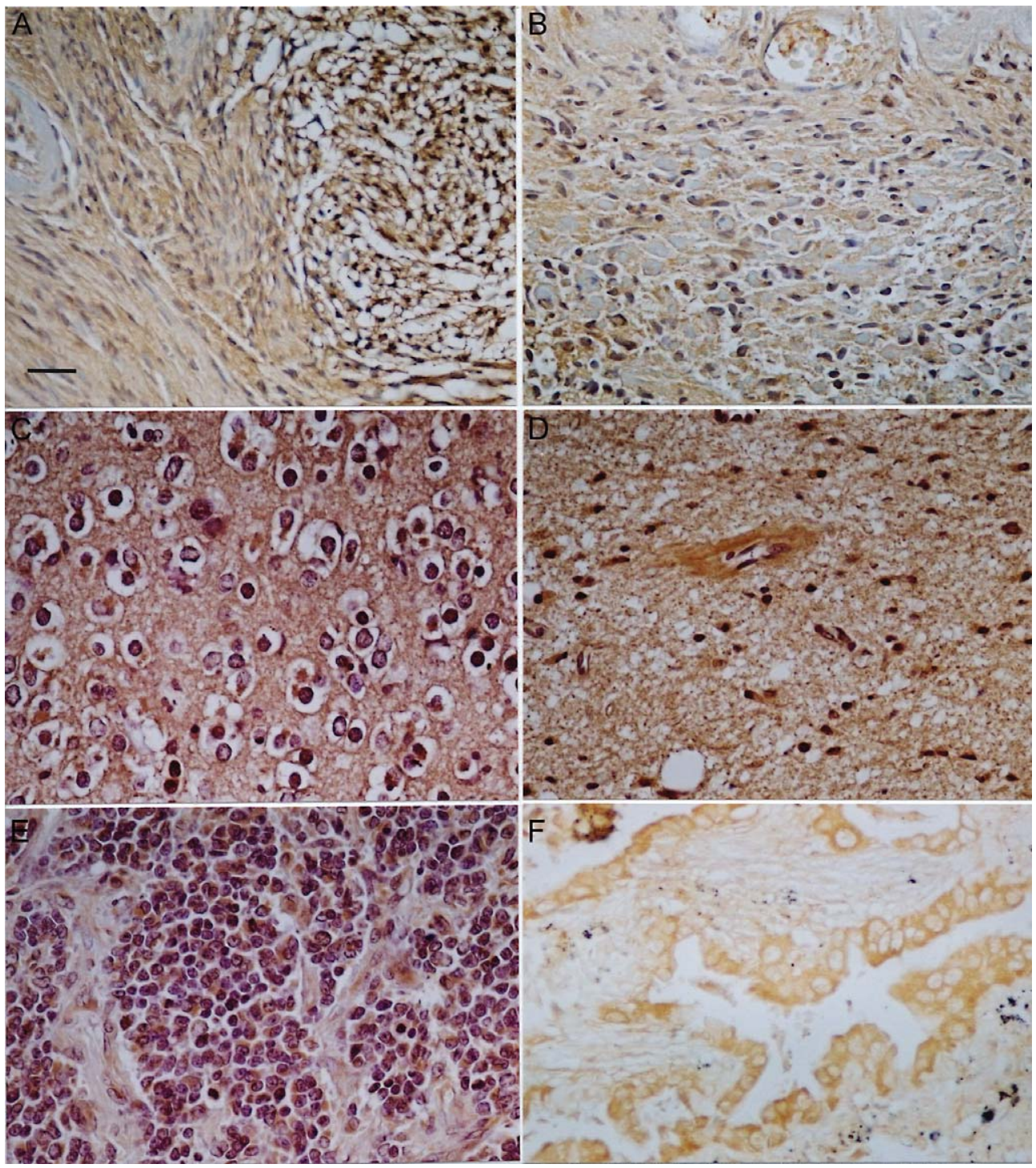

Fig. 3. WOX1 expression in schwannoma (a, b), astrocytoma/gliobalstoma and ependymoma tumors (c-f). The spindle cells with very small, dark nuclei and wavy cytoplasmic processes in schwannoma obtained from the cerebellopontine angle were immunostained intensely compared to fibroblast-like tumor cells with elongated nuclei (a). Moderate expression was present in another case with diverse cellular patterns, located between negative-staining collagenous and sclerosing tissues (b). In astrocytoma cases, the levels of WOX1 were relatively low in the lowgrade astrocytomas, such as pilocytic type (data not shown). In the case with oligodendroglioma and astrocytoma mixed tumors (grade II), immunostaining was moderately present in the matrix of non-proliferating round tumor cells (c, d). WOX1 was also strongly expressed in the anaplastic subtypes (e). In the ependymoma case (f), WOX1 expression was expressed in the cytosol of cyst-lining cells. Bar $=50 \mu \mathrm{m}$.

Fig. 2. Differential expression for WOX1 in transitional (a-f) and atypical $(\mathrm{g}, \mathrm{h})$ meningiomas. The progressive sclerotic and osseous changes were observed in these cases. The staining pattern in some cases was similar to that of malignant types, located on small whorls, rather than on large ones (a, b). WOX1-positive profiles were observed either in the cytosol of polygonal/oval moderate tumor cells or on the nuclei of small or spindle cells (c). In general, the expression of WOX1 was intense in the meningiotheliomatous area and weak in the fibroblastic area (d, e). Low to moderate staining was present in other subtypes such as fibroblastic meningiomas (f). Further, the tumor profiles and WOX1 expression in atypical meningiomas were full of variety like transitional subtypes. $\mathrm{g} \& \mathrm{~h}$ show that WOX1 expression was moderately expressed in tumor whorls but was weakly present in another cases without cluster formation. Bar $=50 \mu \mathrm{m}$. 


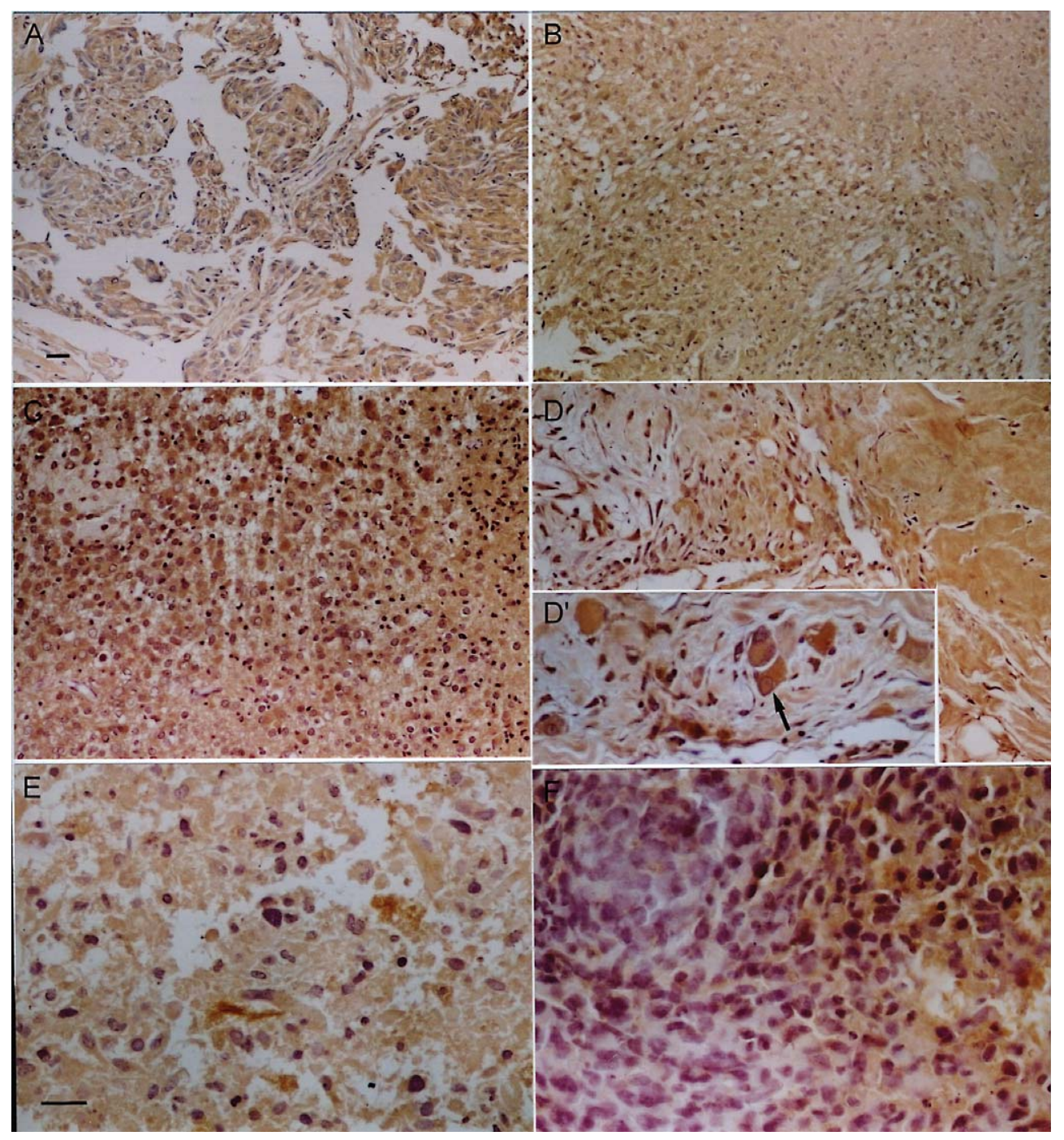

Fig. 4. Specific antibodies for WOX1 phosphorylation at Tyr33 (p-WOX) also indicated a similar immoreactive pattern to WOX1. Moderate to high immunopositive staining was observed in malignant meningioma (a), schwannoma (b), anaplastic astrocytoma (c, d), and grade VI glioblastoma (e, f). Under higher magnification, p-WOX expression could be observed in the nuclei of large tumor cells (arrow in d') and proliferative small cells (f). Bar in a also for b, $\mathrm{c}$ and d. Bar in e is also for d' and f. Bar $=50 \mu \mathrm{m}$.

The tumors of transitional meningiomas consisted largely of spindle fibroblast-like cells, forming loose fascicular patterns (Fig. 2a-e). Progressive sclerotic and osseous changes were observed in these cases. In the transitional type, the staining intensity and profiles were differential. The staining pattern in some cases was similar to that of the malignant types, located on small whorls, rather than on large ones (Fig. 2a, b). WOX1-positive profiles were observed either in the cytosol of polygonal/oval moderate tumor cells or on the nuclei of small or spindle cells (Fig. 2c). In general, the expression of WOX1 was intense in the meningiotheliomatous area and weak in the fibroblastic area (Fig. 2d, e). Low to moderate staining was present in other subtypes, such as fibroblastic meningioma. Figure $2 \mathrm{f}$ shows that the fibrous type had sparse to moderate cellular proliferation, spindle cells arranged either haphazardly or in loose fascicles, and was associated with dense intercellular collagen. The WOX1 expression was weak in this tumor type. Further, the tumor profiles and WOX1 expression in atypical meningiomas were full of variety like transi- 
tional subtypes. Figure $2 \mathrm{~g}$ and $2 \mathrm{~h}$ show that WOX1 expression was moderately expressed in tumor whorls (Fig. 2g), but weakly present in another case without cluster formation (Fig. 2h).

In other nervous system tumors, various levels of WOX1 and p-WOX expression were also detected. Figure $3 \mathrm{a}$ and $3 \mathrm{~b}$ show their expression in schwannomas obtained from the cerebellopontine angle. The spindle cells with very small dark nuclei and wavy cytoplasmic processes were immunostained intensely as compared with fibroblast-like tumor cells with elongated nuclei (Fig. 3a). Moderate expression was present in another group of tumor cells located between negative-staining collagenous and sclerosing tissues (Fig. 3b). WOX1 expression appeared in some nuclei of the diverse cellular patterns. In general, the levels of WOX1 were relatively low in the low-grade astrocytomas, such as pilocytic type (data not shown). In the case with oligodendroglioma and astrocytoma mixed tumors (grade II), immunostaining was moderately present in the matrix of non-proliferating round tumor cells (Fig. 3c, d). The primary tumor-like area with small vesicles and sparse nuclei was also immunopositive. Moreover, WOX1 was strongly expressed in the anaplastic astrocytomas (Fig. 3e). Notably, the intensity of WOX1 expression was higher in the growing clusters with increased cellularity than in peripheral spindle cells. In the ependymoma case, WOX1 expression was expressed in the cytosol of cyst-lining cells (Fig. 3f). We verified our observations by histological grading and showed different profiles for WOX1 immunoreactivity in different nervous system tumors in Table 1.

Phosphorylation of WOX1 at Tyr 33 (p-WOX) was also detected by specific antibodies. The immunoreactive profiles were similar to those of WOX1. Figure 4 shows moderate to high immunopositive staining in malignant meningioma, schwannoma, anaplastic astrocytoma, and grade VI glioblastoma. In some cases, $\mathrm{p}$-WOX expression was observed in the nuclei of large malignant tumor cells (Fig. 4d) and proliferative small cells (Fig. 4f).

\subsection{WWOX mRNA in meningiomas in situ hybridization}

To maximize the specificity for the full-length WWOX mRNA by in situ hybridization, we selected exon 8-9 of the human WWOX gene to design both sense and antisense probes. Half of the collected specimens from meningiomas and astrocytomas were reacted with the non-isotopic anisense probe. Hybridization showed that a low level of WWOX mRNA expression was observed in the normal cortex area (Fig. 5a), whereas WWOX mRNA levels were obvious in some tumors (Fig. 5b, c). The staining pattern and intensity resembles that by immunohistochemistry both in malignant tumor $(5 \mathrm{~b}-\mathrm{d})$ and transitional subtypes $(5 \mathrm{e}-\mathrm{h})$.

\subsection{Ultrastructure of WOX1 expression and colocalization of WOX1 and merlin detected by Immuno-EM}

As memtioned earlier, WOX1 proteins were present in the cytosol or nucli in different types of meningiomas. In the microcystic meningioma case, numerous 10 and $20 \mathrm{~nm}$ gold-particles for WOX1 and merlin in small meningothelial cells were distributed around the nucleus (Fig. 6a, b, d). Co-localization of WOX1 and NF2-immunolabeled particles was also present on cytosol, such as the mitochondria and secreting vesicles (Fig. 6d, e). On condensed, degeneration-like nuclei, WOX1- and merlin-positive particles were also co-expressed (Fig. 6c). Figure $6 f$ to $6 \mathrm{~h}$ show numerous gold particles for phosphorylated WOX1 in the cytosolic organelles, such as rER and ribosomes as well as the nucleus. In the transitional case, both WOX1- and merlin-positive gold particles were co-expressed in moderate cells with round or oval nuclei (Fig. 7a,b). In the atypical case, in both small or moderate cells with elongated or oval nuclei, gold particles were few, as described earlier (Fig. 7c, d). Under higher magnification, very few immunolabeled particles appeared in these cases either in the nucleus or cytoplasm (Fig. 7e).

\subsection{Western blotting assay}

By immunoblotting, WOX1 expression also showed different levels in different meningiomas. Using different antibodies (wox-G from Santa Cruz, wox-N2 from Oncogene), a similar pattern was labeled. The data showed high levels of the WOX1 protein in the microcystic case (case 2) as compared with the normal control (c), atypical case (1) and transitional cases (3-6). Further evidence also shows that a high level of NF2/merlin expression in the microcystic menin- 


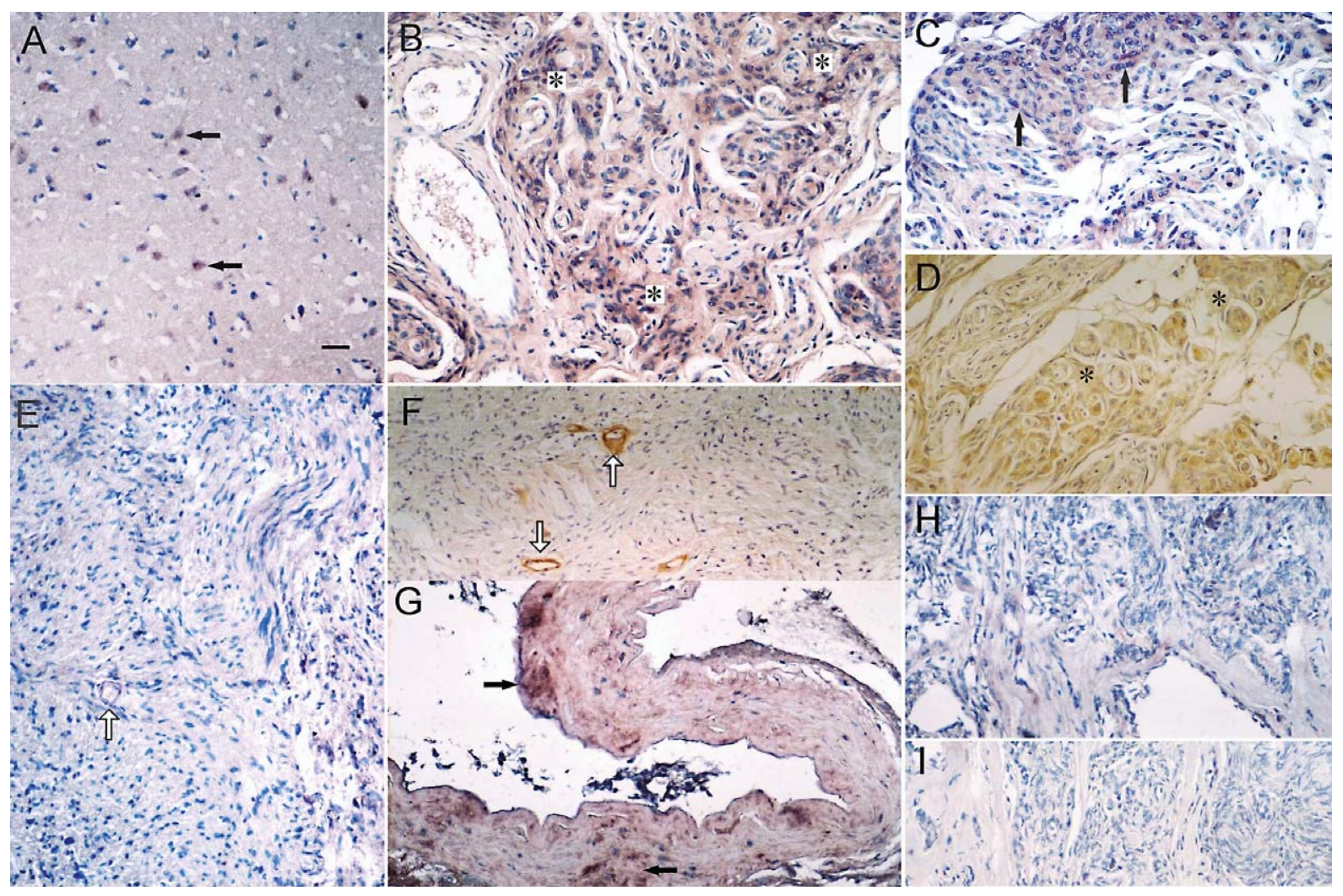

Fig. 5. By in situ hybridization, the staining intensity and _expression pattern of WWOX mRNA resembles that of immunoreactivity. In normal brain tissue, low to moderate _expression for WWOX mRNA was present in some cortical neurons (a). WWOX mRNA appeared high in the small whorls of malignant meningioma (b, c), resembling its protein _expression by immunohistochemistry (d). Low levels of WWOX mRNA _expression were observed in tumor cells of transitional meningiomas (e). Note that some small capillaries (arrows in e \& f) were positive for WWOX mRNAs and proteins (f). Interestingly, WWOX mRNA was also expressed moderately in some large blood vessels (g). Similar patterns for WWOX mRNA were also found in another transitional meningiomas (h). Negative control is shown in (i). Bar $=50 \mu \mathrm{m}$.

giomas (case 2), while WOX 1 (and possibly WOX 3) was similarly present in the transitional (cases 1 and 3) and microcystic cases. Very low WOX1 or NF2/merlin expression was detected in the atypical case (case 4).

\section{Discussion}

By immunohistochemistry, we have determined for the first time that tumor suppressor WOX1 mRNAs and proteins are upregulated in nervous system tumors, whereas WOX1 expression is normally present in the neuronal axons and nerve bundles such as corpus callosum and striatal fascicles. WOX1 labeling and Tyr 33 phosphorylation also showed a positive correlation with the grade of malignancy in the nervous system tumors, in accordance with the WHO classification. In the collected $40 \mathrm{~s}$ cases, WOX1 expression was highly present in the microcystic and malignant meningiomas, anaplastic astrocytoma and glioblastoma multiforme. In contrast, the levels of WOX1 were relatively low in low-grade meningiomas and gliomas, such as the fibroblastic type. Metastatic carcinomas and embryonal tumors stained weakly for WOX1. Ultrastructurally, nuclear translocation was obvious in certain cases and tumor cells. For instance, nuclear and cytosolic WOX1 or p-WOX was strongly expressed in small spindle cells in high-grade meningiomas and schwannomas. In benign or non-aggressive tumors, WOX1 was primarily located in the cytoplasm without any or few translocating to the nuclei. The observations are parallel to those in previous studies in that nuclear translocation is important for the hyperplasia and cancerous proliferation in specific tumor cells [9]. However, WOX1 localization is very variable. We have shown that the majority of upregulated proteins and Tyr33 phosphorylation were located mainly 

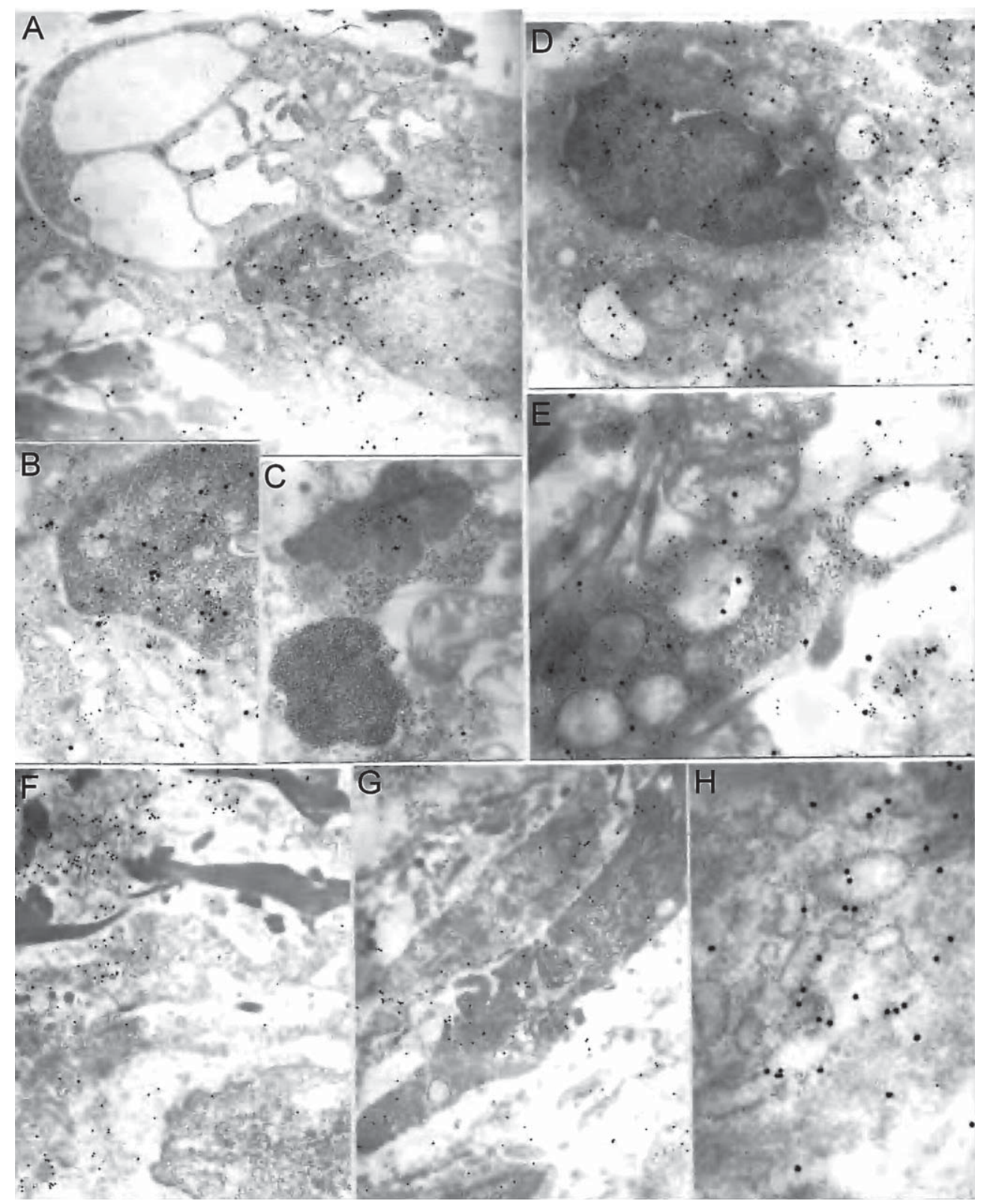

Fig. 6. Electron microscopy indicating WOX1/merlin (a-e) and p-WOX (f-h) expression in microcystic meningiomas. Double immunostaining (a-e) shows co-expression of NF2/merlin (labeled by $20 \mathrm{~nm}$ anti-rabbit gold particles) and WOX1 (10 nm anti-goat gold particles). Large vesicles were found in these tumor cells. Note that the particles were primarily present in the nucleus or around the nuclear membrane (a, b). Some gold particles appeared in condensed nuclei (c). A similar pattern appeared in another cell (d). Note gold particles for WOX1 and merlin were also distributed in ribosomes, secretion-like vesicles and mitochondria (e). Further, p-WOX-labeled gold particles were also detected in the cytoplasm (f-h). Origin magnification: a, c, f, g,10,000X; b, d, e, h, 80,000X.

in the mitochondria in the stress-treated cell lines, prostate/ breast cancer cells and light-injured photoreceptors $[9,11,12,15]$. In the present study, by electron microscopy, numerous WOX1-labeled gold particles were distributed in the rER, secretory vesicles, and collagenous fibers, as well as the condensed, debrislike nuclei, rather than in the mitochondria, indicating multiple roles for WOX1. 

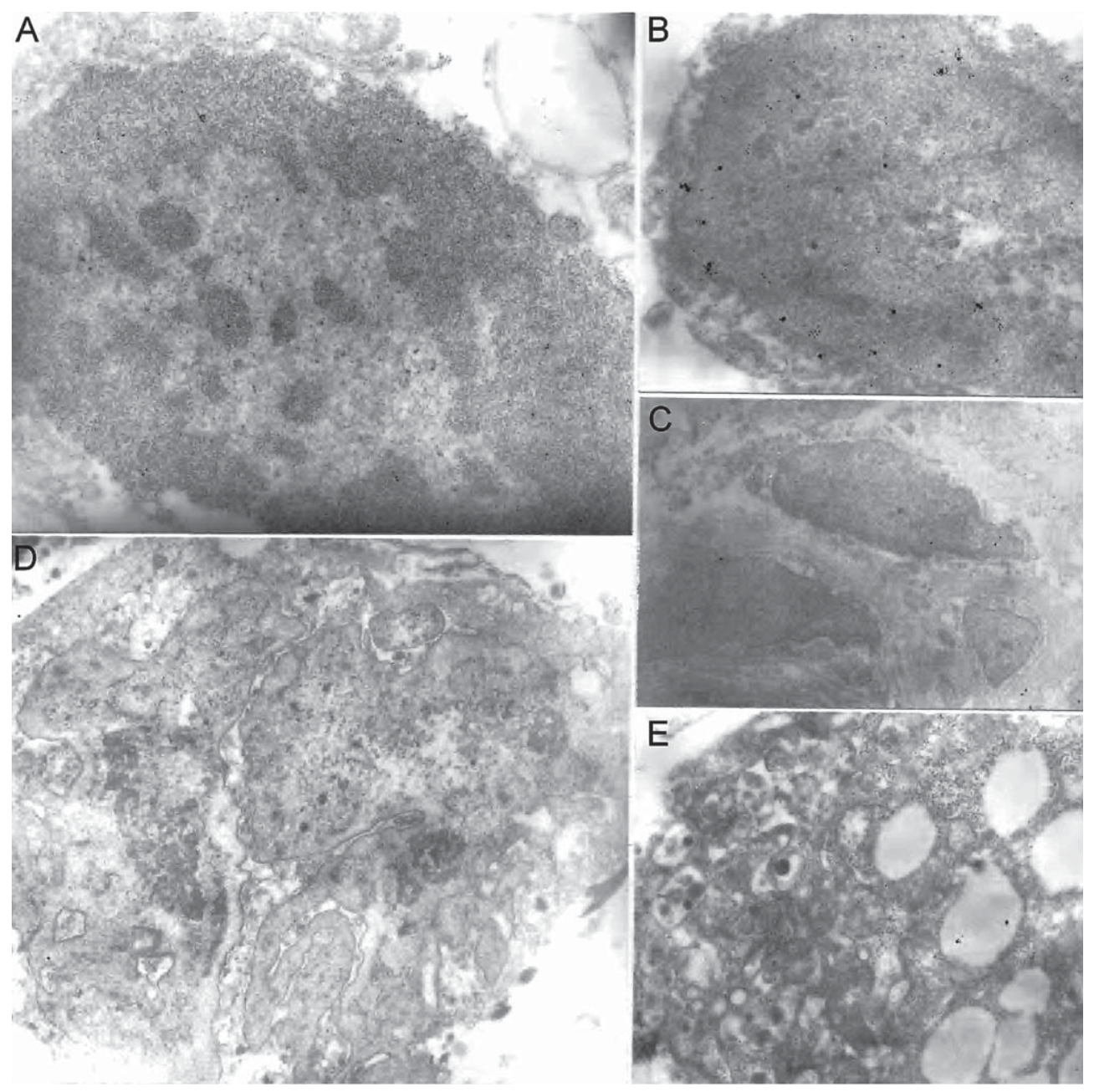

Fig. 7. Low immunoreactivity either for WOX1 (10 $\mathrm{nm}$ particles) or merlin ( $20 \mathrm{~nm}$ particles) in transition meningiomas as shown by electron microphotographs.

WOX1 activation may also indicate the progression of tumor cells in relation to their hyperplasia, cancerous and malignancy. Recently, we demonstrated that upregulation and activation of WOX1 supports the prostate and breast carcinogenesis to pre-metastatic state [9]. We also indicated the procession of cutaneous squamous cell carcinoma is associated with WOX1 activation and expression [10]. Nonetheless, the reduced WWOX staining in invasive lung, breast and bladder cancers is associated with WWOX hypermethylation patterns. Here, the results that low levels of WOX 1 expression present in the metastastic tumors in the brain or spinal cord suggest WOX1contributing in local hyperplasia and carcinogenesis but not in metastasis.
Neurofibromatosis type 2 (NF2) is an inherited disorder that leads to the occurrence of schwannoma and meningiomas $[17,18]$. NF2 loss plays a large role in both tumor development and metastasis. The NF2 gene encodes merlin. Merlin, a tumor suppressor, interacts with a number of protein partners and inhibits many growth signal pathways when overexpressed. Further, the NF2/merlin status of meningiomas is associated with tumor localization and histology [23]. In this study, we have determined the immunostaining patterns and intensity of $\mathrm{NF} 2 /$ merlin in meningiomas, which resemble WOX1 expression. By electron microscopy, colocalization of WOX1 and merlin can be detected in certain cell types, such as moderate tumor cells in microcystic, malignant and some transitional menin- 
$\mathbf{A}$
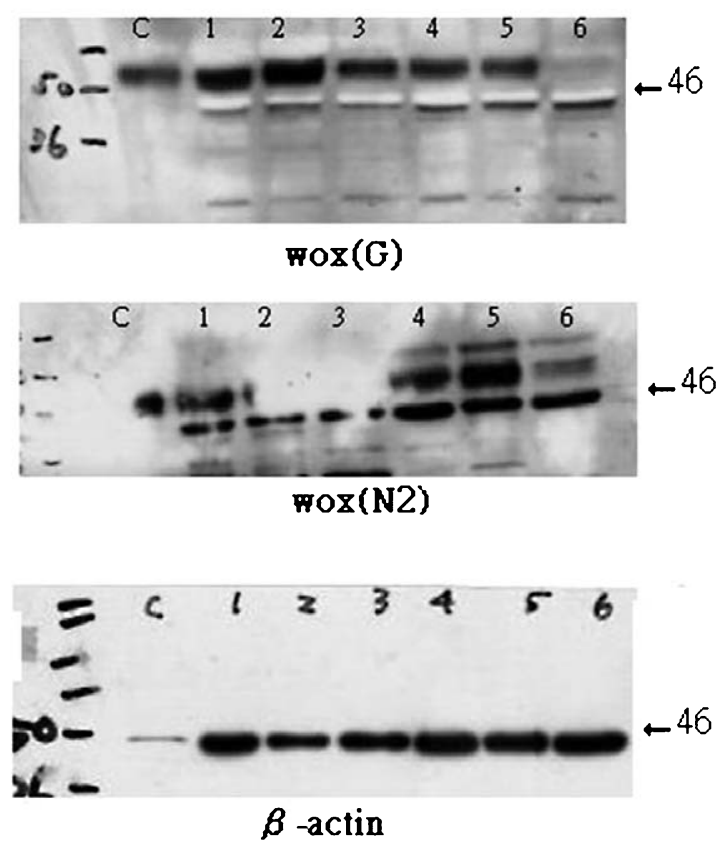

B
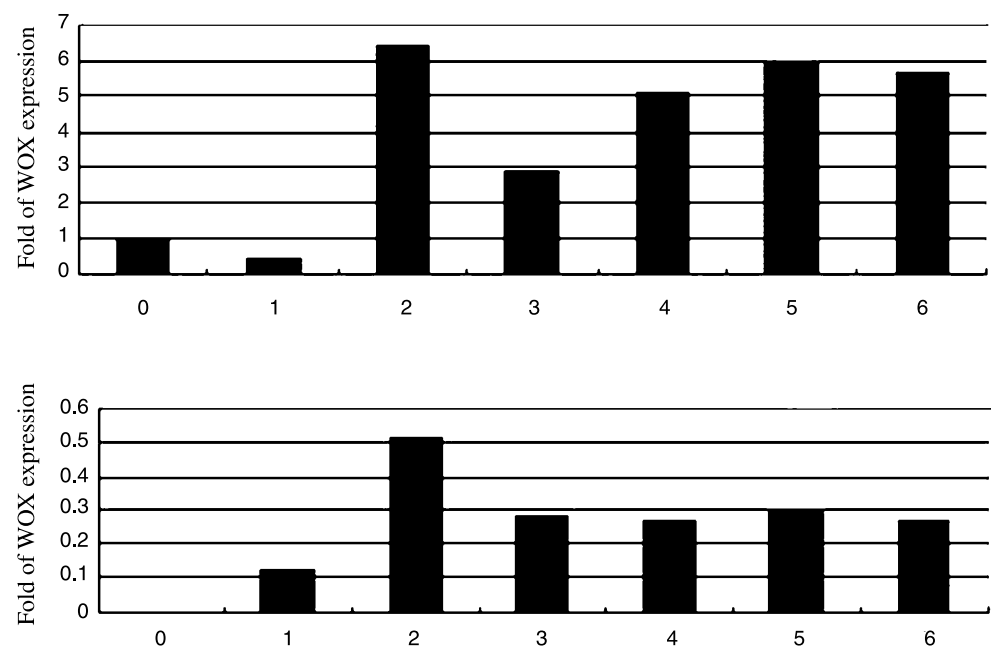

Fig. 8. Western blotting assay indicated WOX1 expression in different meniomas using different antibodies, wox (N2) obtained from Oncogene and wox (G) from Santa Cruz. c, control; 1, atypical type; 2, microcystic type; 3-6, transition types.

giomas. Merlin is considered a positive regulator of $\mathrm{p} 53$ in terms of tumor suppressor activity by neutralizing the inhibitory effect of Mdm-2 [22]. The praline-rich region of p53 binding with WW domains of WOX1 induces apoptosis in a synergisatic manner [11]. p53WOX1 may act as a merlin binding partner in certain cells; it is not yet clear which of these tumor suppressors regulates tumor development synergistically.
Until now, the mechanisms of tumorigenesis generally have been explained primarily by the mutations of oncogenes or tumor suppressors. As mentioned earlier, WOX1 physically interacts with tumor suppressor p53 [11]. WWOX expression also triggers the redistribution of nuclear p73, a p53 homologue, to the cytoplasm, and then suppresses its transcriptional activity [5]. Several studies have reported that p53 labeling or p53 


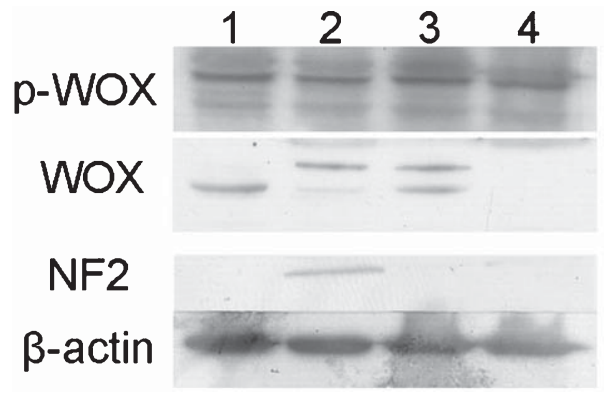

Fig. 9. Western blot data showing 2-immunoreactive bands for WOX 1 and WOX 2 in meningiomas, 1 and 3 from transitional case, 2 for microcystic type and 4 from atypical type. The results are similar to those of Fig. 8 and immunostaining.

gene deletion shows a positive correlation with the grade of malignancy of astrocytomas or meningiomas $[24,25]$, although some studies show different results [26]. Bc-2 and p53 exhibit a similar staining pattern in meningiomas. These cases expressing oncogene Bcl2 protein presented a high proportion of proliferating cells in $\mathrm{S}$ phase. We have also observed high levels of $\mathrm{Bcl}-2$ and mutant p53 gene products in some aggressive nerve system tumors (unpublished data). However, the upregulation of $\mathrm{p} 53 / \mathrm{Bcl}-2$ was mainly expressed in collagen-like fibers, only a few of immunopositive tumor cells were observed. The profile was different from that of WOX1/p-WOX or merlin. The relationship between WOX1 and other tumor suppressors or oncogenes is intriguing. We previously reported that overexpression of WOX1 preferentially inhibited viability and induced apoptosis in human glioblastoma cells expressing mutant $\mathrm{p} 53$ in vitro [27]. It implies that the survival of human glioblastoma cells may depend on interactions between the gain-of-function of p53 and WOX1.

As described above, WWOX is located at a common fragile region on chromosome 16q23.3 [1] and exhibits genomic alterations in lung, breast and other cancers $[3,4]$. Point mutation in the gene are infrequent but deletions occur frequently [1]. In this study, we have examined the loss of heterozygosity $(\mathrm{LOH})$ in our collected meningioma cases $(n=3)$, but no gene mutation was detected. Although the NF2 gene mutation is well known in meningiomas, we found that WOX1 and NF2 protein was colocalized in some tumor cells. This correlation may need further validation using more clinical specimens.

\section{Acknowledgments}

We thank Miss Tzu-Chun Wang and ShinYe Hsu for technical assistance. This work was supported by the National Science Council of Republic of China (NSC92-2320-B006-079) to S.T.C. and (NSC-93-2314-B-195-025, 98-2314-B-195-004MY3) to M.F.C. This study also was supported by the grant (MMH-9401) from the Department of Medical Research, Mackay Memorial Hospital, Taipei, Taiwan.

\section{References}

[1] A.K. Bednarek, K.J. Laflin, R.L. Daniel, Q. Liao, K.A. Hawkins and C.M. Aldaz, WWOX, a novel WW domaincontaining protein mapping to human chromosome 16q23.324.1 , a region frequently affected in breast cancer, Cancer Res 60 (2000), 2140-2145.

[2] K. Ried, M. Finnis, L. Hobson, M. Mangelsdorf, S. Dayan, J.K. Nancarrow, E. Woollatt, G. Kremmidiotis, A. Gardner and D. Venter, et al., Common chromosomal fragile site FRA16D sequence: Identification of the FOR gene spanning FRA16D and homozygous deletions and translocation breakpoints in cancer cells, Hum Mol Genet 9 (2000), 1651-1663.

[3] A.J. Paige, K.J. Taylor, C. Taylor, S.G. Hillier, S. Farrington, D. Scott, D.J. Porteous, J.F. Smyth, H. Gabra and J.E. Watson, WWOX: A candidate tumor suppressor gene involved in multiple tumor types, Proc Natl Acad Sci U S A 98 (2001), 11417-11422.

[4] K. Driouch, H. Prydz, R. Monese, H. Johansen, R. Lidereau and $\mathrm{E}$. Frengen, Alternative transcripts of the candidate tumor suppressor gene, WWOX, are expressed at high levels in human breast tumors, Oncogene 21 (2002), 1832-1840.

[5] R.I. Aqeilan, V. Donati, A. Palamarchuk, F. Trapasso, M. Kaou, Y. Pekarsky, M. Sudol and C.M. Croce, WW domaincontaining proteins, WWOX and YAP, compete for interaction with ErbB-4 and modulate its transcriptional function, Cancer Res 65 (2005), 6764-6772.

[6] H. Ishii and Y. Furukawa, Alterations of common chromosome fragile sites in hematopoietic malignancies, Int J Hematol 79 (2004), 238-242.

[7] S.W. Park, J. Ludes-Meyers, D.B. Zimonjic, M.E. Durkin, N.C. Popescu and C.M. Aldaz, Frequent downregulation and loss of WWOX gene expression in human hepatocellular carcinoma, Br J Cancer 91 (2004), 753-759.

[8] C. Gourley, A.J. Paige, K.J. Taylor, D. Scott, N.J. Francis, R. Rush, C.M. Aldaz, J.F. Smyth and H. Gabra, WWOX mRNA expression profile in epithelial ovarian cancer supports the role of WWOX variant 1 as a tumour suppressor, although the role of variant 4 remains unclear, Int J Oncol 26 (2005), 1681-1689.

[9] N.S. Chang, L. Schultz, L.J. Hsu, J. Lewis, M. Su and C.I. Sze, 17beta-Estradiol upregulates and activates WOX1/WWOXv1 and WOX2/WWOXv2 in vitro: Potential role in cancerous progression of breast and prostate to a premetastatic state in vivo, Oncogene 24 (2005), 714-723. 
[10] F.J. Lai, C.L. Cheng, S.T. Chen, C.H. Wu, L.J. Hsu, J.Y. Lee, S.C. Chao, M.C. Sheen, C.L. Shen and N.S. Chang, et al., WOX1 is essential for UVB irradiation-induced apoptosis and down-regulated via translational blockade in UVB-induced cutaneous squamous cell carcinoma in vivo, Clin Cancer Res 11 (2005), 5769-5777.

[11] N.S. Chang, N. Pratt, J. Heath, L. Schultz, D. Sleve, G.B. Carey and N. Zevotek, Hyaluronidase induction of a WW domaincontaining oxidoreductase that enhances tumor necrosis factor cytotoxicity, J Biol Chem 276 (2001), 3361-3370.

[12] N.S. Chang, J. Doherty and A. Ensign, JNK1 physically interacts with WW domain-containing oxidoreductase (WOX1) and inhibits WOX1-mediated apoptosis, J Biol Chem 278 (2003), 9195-9202.

[13] N.S. Chang, J. Doherty, A. Ensign, L. Schultz, L.J. Hsu and Q. Hong, WOX1 is essential for tumor necrosis factor-, UV light-, staurosporine-, and p53-mediated cell death, and its tyrosine 33-phosphorylated form binds and stabilizes serine 46-phosphorylated p53, J Biol Chem 280 (2005), 43100-43108.

[14] S.T. Chen, J.I. Chuang, J.P. Wang, M.S. Tsai, H. Li and N.S. Chang, Expression of WW domain-containing oxidoreductase WOX1 in the developing murine nervous system, Neuroscience 124 (2004), 831-839.

[15] S.T. Chen, J.I. Chuang, C.L. Cheng, L.J. Hsu and N.S. Chang, Light-induced retinal damage involves tyrosine 33 phosphorylation, mitochondrial and nuclear translocation of WW domain-containing oxidoreductase in vivo, Neuroscience 130 (2005), 397-407.

[16] C.I. Sze, M. Su, S. Pugazhenthi, P. Jambal, L.J. Hsu, J. Heath, L. Schultz and N.S. Chang, Down-regulation of WW domaincontaining oxidoreductase induces Tau phosphorylation in vitro, A potential role in Alzheimer's disease. J Biol Chem 279 (2004), 30498-30506.

[17] D.G. Evans, M. Sainio and M.E. Baser, Neurofibromatosis type 2, J Med Genet 37 (2000), 897-904.

[18] M.E. Baser, R.E. DG and D.H. Gutmann, Neurofibromatosis 2, Curr Opin Neurol 16 (2003), 27-33.
[19] G.H. Xiao, J. Chernoff and J.R. Testa, NF2: The wizardry of merlin, Genes Chromosomes Cancer 38 (2003), 389-399.

[20] R.J. Shaw, J.G. Paez, M. Curto, A. Yaktine, W.M. Pruitt, I. Saotome, J.P. O’Bryan, V. Gupta, N. Ratner and C.J. Der, et al., The Nf2 tumor suppressor, merlin, functions in Rac-dependent signaling, Dev Cell 1 (2001), 63-72.

[21] K. Kaempchen, K. Mielke, T. Utermark, S. Langmesser and C.O. Hanemann, Upregulation of the Rac1/JNK signaling pathway in primary human schwannoma cells, Hum Mol Genet 12 (2003), 1211-1221.

[22] H. Kim, N.J. Kwak, J.Y. Lee, B.H. Choi, Y. Lim, Y.J. Ko, Y.H. Kim, P.W. Huh, K.H. Lee and H.K. Rha, et al., Merlin neutralizes the inhibitory effect of Mdm2 on p53, J Biol Chem 279 (2004), 7812-7818.

[23] J. Kros, K. de Greve, A. van Tilborg, W. Hop, H. Pieterman, C. Avezaat, R. Lekanne Dit Deprez and E. Zwarthoff, NF2 status of meningiomas is associated with tumour localization and histology, J Pathol 194 (2001), 367-372.

[24] T. Yakut, A. Bekar, M. Doygun, H. Acar, U. Egeli and E. Ogul, Evaluation of relationship between chromosome 22 and p53 gene alterations and the subtype of meningiomas by the interphase-FISH technique, Teratog Carcinog Mutagen 22 (2002), 217-225.

[25] S.M. Ranuncolo, M. Varela, A. Morandi, J. Lastiri, S. Christiansen, E. Bal de Kier Joffe, M.G. Pallotta and L. Puricelli, Prognostic value of Mdm2, p53 and p16 in patients with astrocytomas, J Neurooncol 68 (2004), 113-121.

[26] P.H. Aguiar, C. Agner, R. Simm, A.B. Freitas, A.M. Tsanaclis and P. Plese, p53 Protein expression in meningiomas - a clinicopathologic study of 55 patients, Neurosurg Rev 25 (2002), 252-257.

[27] M.F. Chiang, S.T. Yeh, H.F. Liao, N.S. Chang and Y.J. Chen, Overexpression of WW domain-containing oxidoreductase WOX1 preferentially induces apoptosis in human glioblastoma cells harboring mutant p53, Biomed Pharmacother 66 (2012), 433-438. 


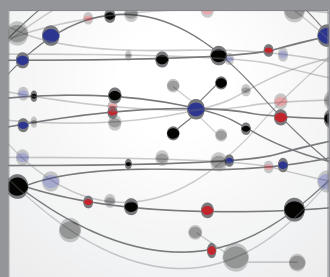

The Scientific World Journal
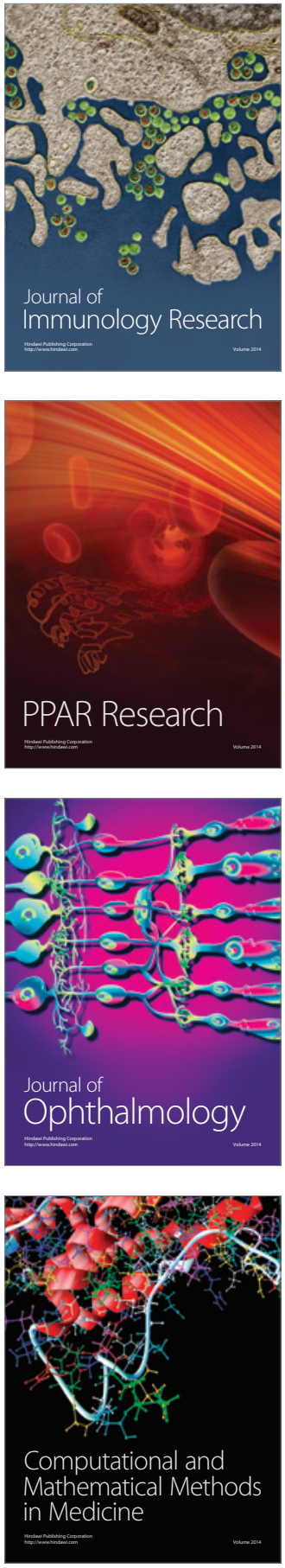

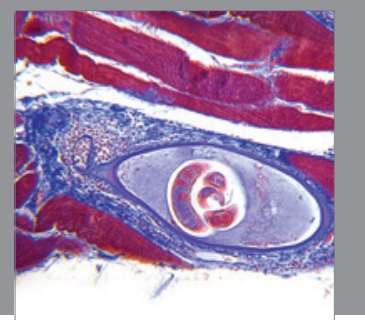

Gastroenterology

Research and Practice
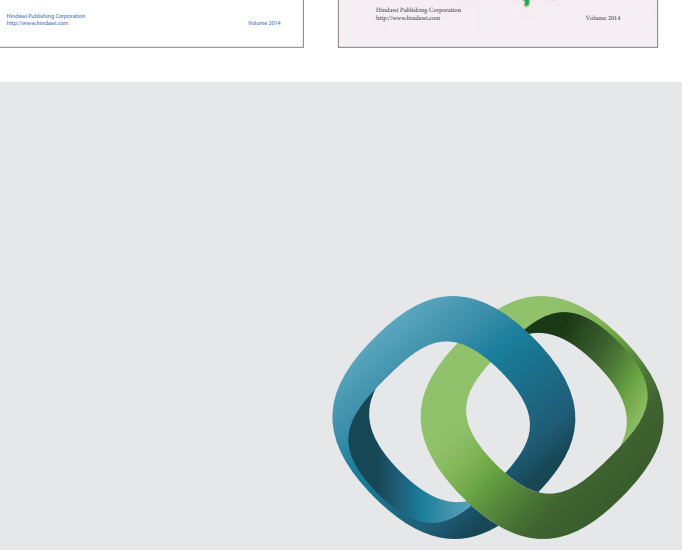

\section{Hindawi}

Submit your manuscripts at

http://www.hindawi.com
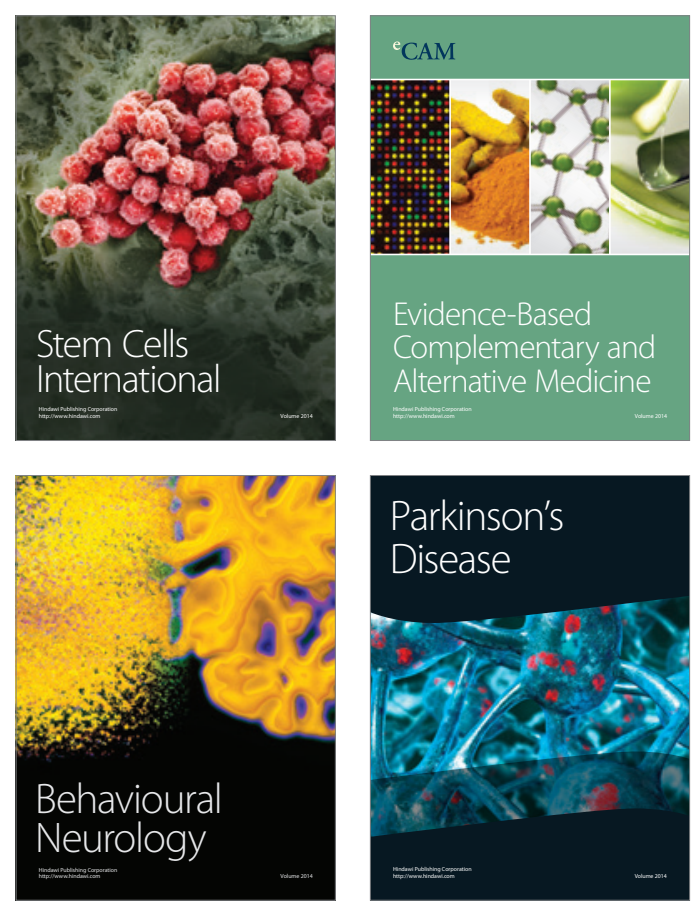

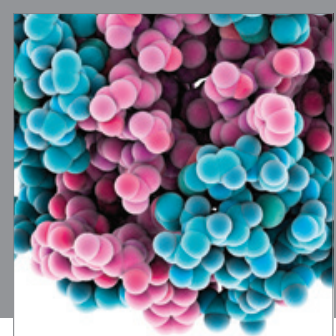

Journal of
Diabetes Research

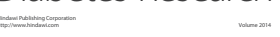

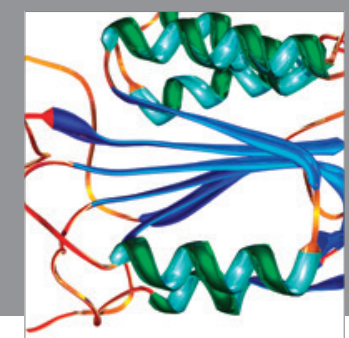

Disease Markers
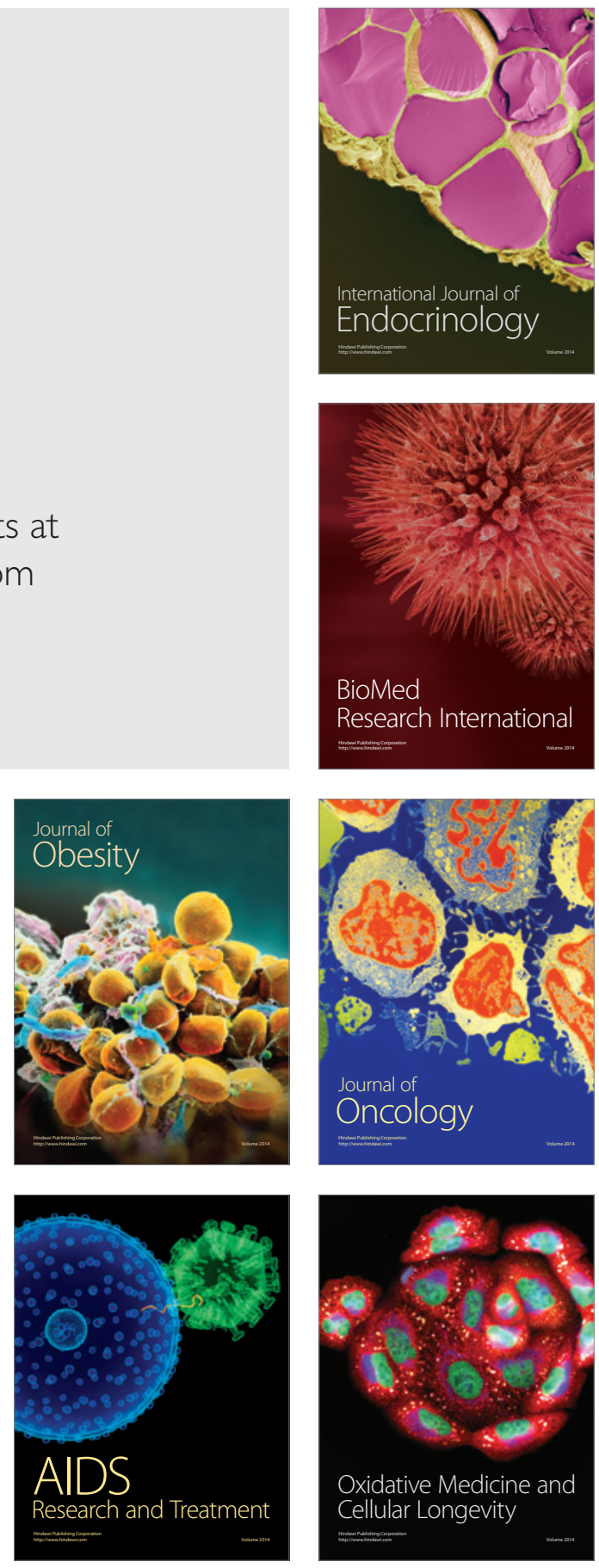